experience: "We would add in evidence of the suffering from which the wrecked party were relieved that in consequence of his exposure, Capt. Holmes died of consumption after returning to the United States."

Accompanying the above documents is a carefully drawn map, a part of which is reproduced here.

\title{
New Class of Memberships
}

At a meeting of the Council of the Business Historical Society on April 16, it was voted to create a new class of membership, to be known as Junior Memberships. By this arrangement persons who are not eligible to become Affiliated Members will be permitted to belong to the Society upon payment of ten dollars annual dues.

The new membership is designed to interest young men in business who would like to support the work of the Society but who have not reached the point of being able to afford the twenty-five dollars annual dues paid by General Members. The new Junior Memberships are restricted to persons under forty years of age.

This arrangement does not alter the provisions of Affiliated Membership by which persons and institutions connected with some recognized department of educational or literary work are enabled to join for ten dollars annual dues.

Both the Junior and Affiliated Members are entitled to all privileges of membership including that of voting.

\section{Society Members to Receive Valuable Publications in 1937}

Pursuing the Society's purpose of promoting study and publication in the field of Business History, the officers of the Society have again arranged to present books to its members. This plan has the double merit of giving members a substantial return for their financial support and providing a wider and faster distribution to the publications than would otherwise take place.

This year, through the generosity of friends, the Society will present three volumes, as follows: 
Kenneth W. Porter, The Jacksons and the Lees-Two Generations of Massachusetts Merchants 1765-1818 (2 volumes).

N. S. B. Gras, The History of Massachusetts-First National Bank of Boston, 1784-1934.

Dr. Porter's study is now in proof, and the book by Professor Gras will go to press during the summer Both works are being published by the Harvard University Press and will be distributed to members as soon as possible after they are printed.

Since these publications will probably retail for five dollars a volume, members in good standing will receive about fifteen dollars worth of books this year without additional charge. For Junior and Affliated Members this constitutes an especially good return for the annual dues.

\section{Labor Relations in 1857}

With the relations between management and labor being discussed on every hand today, the following notice is of topical interest. It reproduces the contents of a printed communication, now in the Society's collection, which was addressed to the employees of the Boston and Worcester Railroad shortly after the panic of 1857. The metaphor becomes somewhat confused as business changes from a ship in the first paragraph to a machine with wheels in the second, but the tone and logic of the appeal are attractive.

\section{Boston and Worcester Railroad, Boston, Oct. 30, 1857.}

\section{TO THE EMPLOYEES:}

Gentlemen:-The receipts from Passengers and Freight have fallen off, during the last month (as compared with the corresponding month of last year), over TWENTY THOUSAND DOLLARS, with very little prospect of any improvement during the coming winter; thus making a reduction in expenses absolutely necessary. Let $u s$ fully realize this fact, and imagine ourselves in this noble ship, with a valuable cargo, from which its owners expect and are entitled to a return for their investment, and that they are dependent as much upon this return, for the support of their families, as we are upon our wages for the support of ours. Let us also consider that a sudden and unexpected financial storm has come upon us, and with ships, large and small, foundering all 